IRO Journal on Sustainable Wireless Systems (2019)

Vol.01/ No. 04

Pages: 256-264

http://irojournals.com/irosws/

DOI: https://doi.org/10.36548/jsws.2019.4.006

\title{
REVIEW ON SUSTAINABLE GREEN INTERNET OF THINGS AND ITS APPLICATION
}

\author{
Dr. Abul Bashar, \\ Department of Computer Engineering, \\ Prince Mohammad Bin Fahd University, \\ Al Khobar, Kingdom of Saudi Arabia - 31952. \\ Email: abashar@pmu.edu.sa
}

\begin{abstract}
The world is striving to become smart with the latest findings evolved in the communication and the information technology. The emerging of the things that could automatically and intelligently render service to the people in cooperative way acts as a part of this smart world and the internet of things take the significant role in the development of the smart world as it is capable of connecting every tangible things of the world. Though this technological advancement paves way for a seamless and an efficient way of communication, the excess energy consumed by the various add -ons used along with the devices that make the world smart cause environmental pollution and unknown destructions. Multitude of strides researched in improving the energy efficiency in the devices to make the internet of things sustainable and green is reviewed in the paper along with its applications hoping that this would create awareness in the development of the future smart applications.
\end{abstract}

Keywords: Internet of Things, Sustainability, Green IOT, Smart Objects,

\section{INTRODUCTION}

To start with let us go in to the description that explains in detail the internet of things and its essentialities. The major key that paved way for the internet of things is the development in the communication and information technologies and the entailment in the need for the seamless communication and service. The internet of things connecting all the tangible things around us is made possible by many add-ons that help in the, detecting and monitoring the scenario, making the conveyance and the computation possible and following with the service that are to be provided and all these are enabled using the set of protocols and coding to regulate the flow properly. The fig. 1 provided below shows the add-ons or the element that serve as the back bone of the internet of things.

ISSN: 2582-3167 (online) 
IRO Journal on Sustainable Wireless Systems (2019)

Vol.01/ No. 04

Pages: 256-264

http://irojournals.com/irosws/

DOI: https://doi.org/10.36548/jsws.2019.4.006

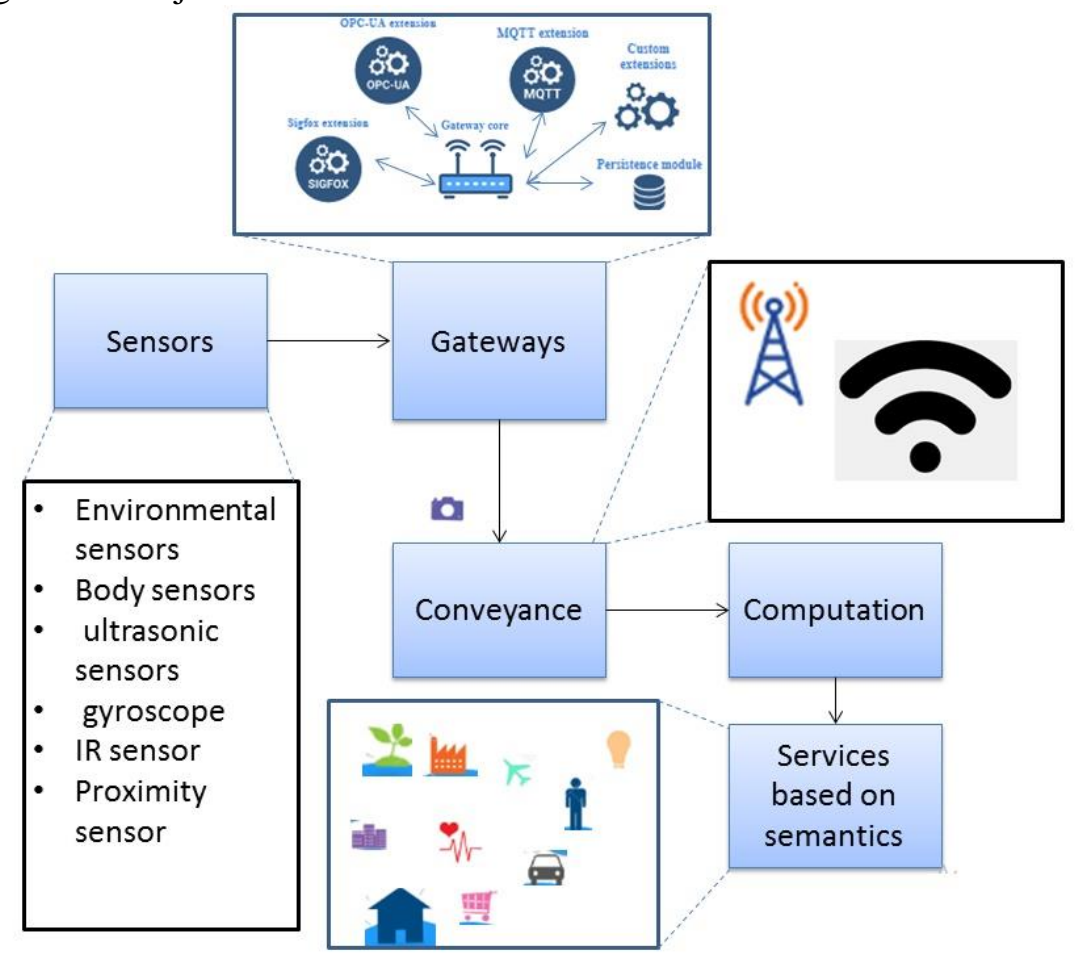

Fig.1.The Elements of Internet of Things

The element in the process of the providing a seamless communication and services consumes more power triggering the sustainability concerns [1]. The energy consumption of the internet of things also introduces toxic pollution and E-waste that affects the surroundings and the ecosystem.

The findings and the proposals to reduce the harmful effects of the internet things, and develop a green internet of things that are sustainable is reviewed in the paper along with the applications of green internet of things. The review is comprised of the methods followed in reducing the harmful effects of the internet of things and the applications that are enriched with the green internet of things. The Review proceeds by gathering of research papers related to the green internet of things using the internet database available and categorizes the paper with section 2 providing the over view of the green internet of things, and its sustainability, section 3 with the applications that employ the green internet of things followed by challenges in deploying Green-IOT in section 4 followed by Conclusion in section .5

ISSN: 2582-3167 (online) 
IRO Journal on Sustainable Wireless Systems (2019)

Vol.01/ No. 04

Pages: 256-264

http://irojournals.com/irosws/

DOI: https://doi.org/10.36548/jsws.2019.4.006

\section{OVER VIEW OF SUSTAINABLE GREEN INTERNET OF THINGS}

The section proceeds with the overview of the sustainable green internet of things based on the survey conducted from the literature gathered. The researchers provide the details of the key components in the internet of things and the different layers that causes the major power consumption creating harmful effects in the environment. The fig. 2 is the detailed picture of the power requirements of the internet of things.

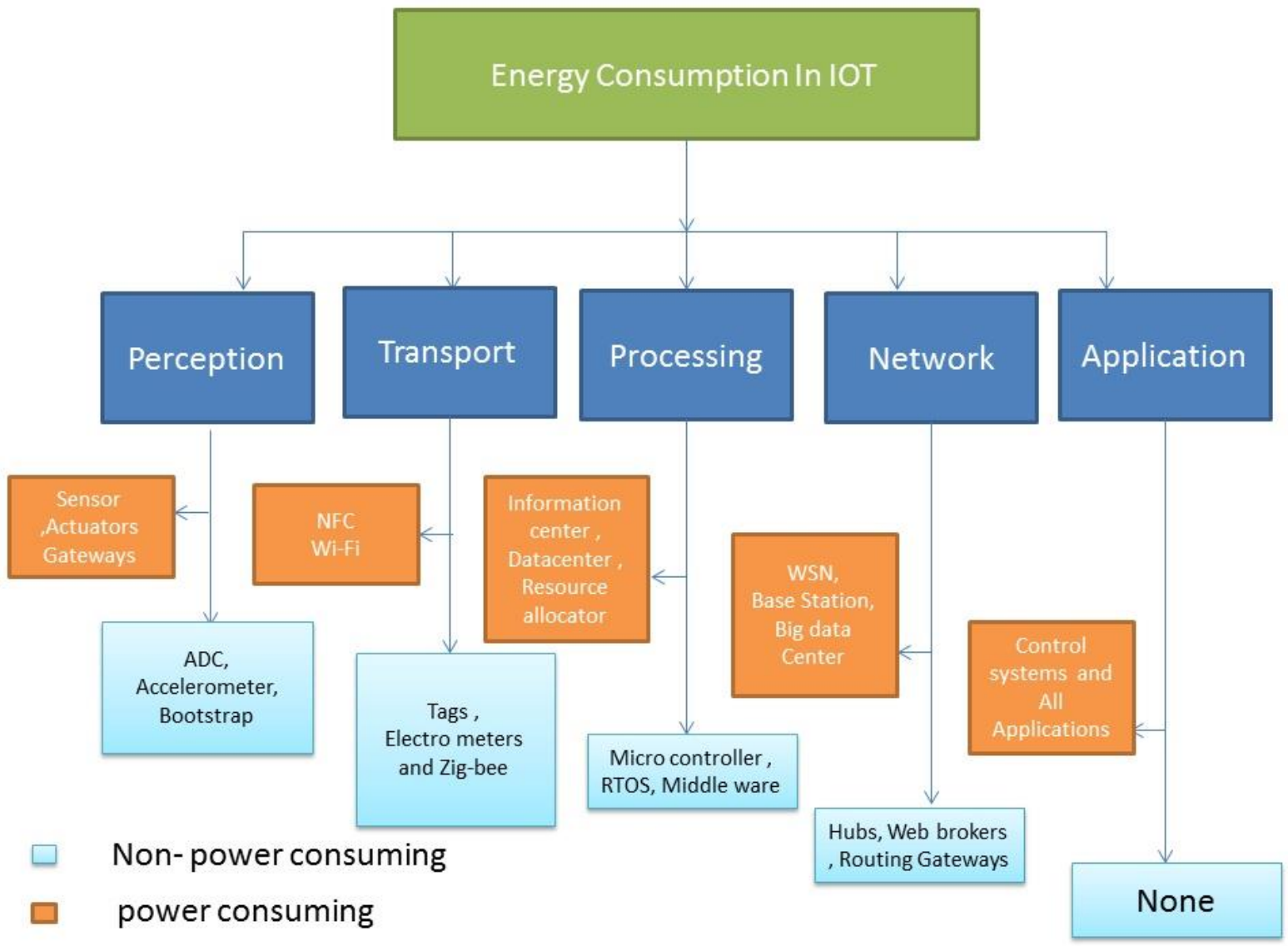

Fig. 2 IOT Layers and the Components

The fig. 2 presenting the frame work of the IOT delivers a clear picture of the layers in the IOT and the components involved in the internet of things and the description of their power consumption. The energy optimization techniques in the IOT have is insisted in all its layers to make it green, eliminating its harmful effects on the

ISSN: 2582-3167 (online) 
IRO Journal on Sustainable Wireless Systems (2019)

Vol.01/ No. 04

Pages: 256-264

http://irojournals.com/irosws/

DOI: https://doi.org/10.36548/jsws.2019.4.006

ecosystem. The author Bol, David et al in the year 2013 suggests the green system on chip for internet of things that includes the complete set of components required for the conveyance and the service provisioning. The chip was designed battery less with a high computing performance at a lower die area and decreased power demands. Then Maksimovic et al in his paper in 2018 presents the "principals and the role of the green internet of things along with the analysis of the significance of the green technologies", as the green technologies potentially enhances our ecosystem and heightens the quality of living, decreasing the negative impact on the health of the human beings as well as the surroundings more researchers concentrate applying the principles of the green technologies to the internet of things the author Maksimovic provides the goals of the green technology and its employment in the IOT to bring down the harms and heighten the benefits. The table.1 below shows the aims of the green technology and the task to be accomplished for satisfying the principles of the green-IOT.

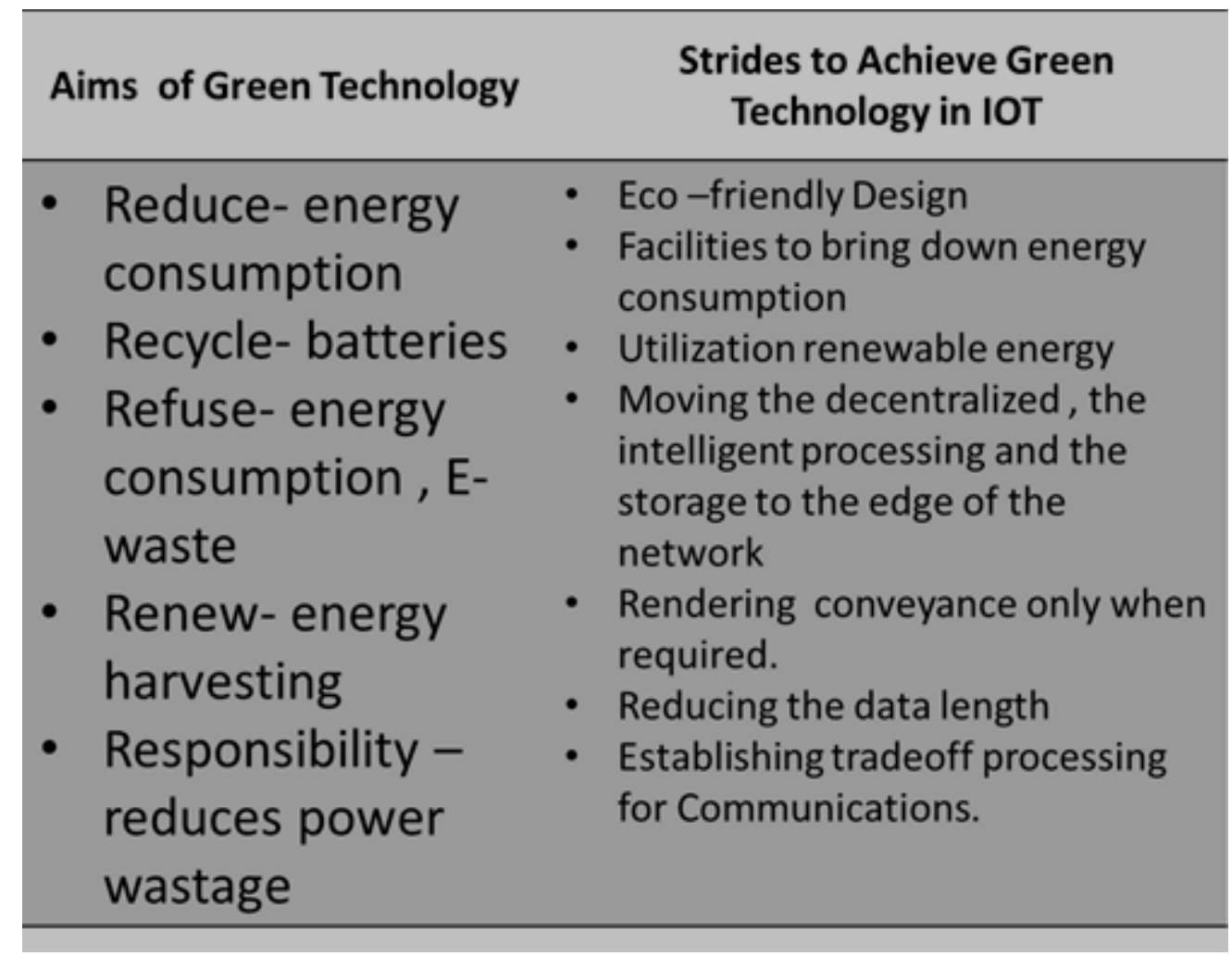

Table.1 Aims and the Strides to Achieve Green technology

Shaikh et al 2015 presents the details of the technology enabling the green internet of things, the details of the technologies such as the green tags that involve the context awareness, active tags, and passive tags, near field

ISSN: 2582-3167 (online) 
IRO Journal on Sustainable Wireless Systems (2019)

Vol.01/ No. 04

Pages: 256-264

http://irojournals.com/irosws/

DOI: https://doi.org/10.36548/jsws.2019.4.006

communication, the green sensors that include nano technologies, embedded systems, wireless sensors and actuators and finally the green internet services that include cloud computing, information sharing, smart web services, knowledge aggregation etc. Mirjana, et al 2017 describes the" Green internet of things and green nanotechnology role in realizing smart and sustainable agriculture." The author Cathryn,et al elaborates the "Performance evaluation of green data centre management supporting sustainable growth of the internet of things." The author describes the development of the green network management employing the optimization techniques to provide a green approach for managing the network. The table.2 presents the summary of the elements involved in the IOT, the reason behind the power consumption and the optimization methods followed and the parametrics that are optimized to develop the green-IOT based on the literature review.

\begin{tabular}{|c|c|c|c|}
\hline Elements & $\begin{array}{l}\text { Reason for Energy } \\
\text { Demands }\end{array}$ & $\begin{array}{l}\text { Energy Optimization } \\
\text { Methods }\end{array}$ & Merits \\
\hline Sensors & $\begin{array}{l}\text { Continuous } \\
\text { Monitoring }\end{array}$ & $\begin{array}{l}\text { Compressed sensing, } \\
\text { sleep scheduling, } \\
\text { selective sensing }\end{array}$ & $\begin{array}{l}\text { Enhancement in } \\
\text { localization of } \\
\text { sensors, mobility } \\
\text { management, delay } \\
\text { management }\end{array}$ \\
\hline $\begin{array}{l}\text { Radio frequency } \\
\text { Identification }\end{array}$ & $\begin{array}{l}\text { Identifying the } \\
\text { monitored data }\end{array}$ & $\begin{array}{l}\text { Employing passives } \\
\text { sensors }\end{array}$ & $\begin{array}{l}\text { Improved } \\
\text { performance }\end{array}$ \\
\hline Destination Nodes & $\begin{array}{l}\text { Examining and } \\
\text { storing of data }\end{array}$ & $\begin{array}{l}\text { Optimization of } \\
\text { computations in the } \\
\text { tasks to core } \\
\text { mapping }\end{array}$ & $\begin{array}{l}\text { Improvement in the } \\
\text { quality of service }\end{array}$ \\
\hline Data Center & $\begin{array}{l}\text { Processing of } \\
\text { information, } \\
\text { performing high } \\
\text { computation task }\end{array}$ & $\begin{array}{l}\text { Proper distribution of } \\
\text { load } \\
\text { Reducing the data } \\
\text { path }\end{array}$ & $\begin{array}{l}\text { Heightened } \\
\text { Throughput }\end{array}$ \\
\hline Gateways & $\begin{array}{l}\text { Establishing link } \\
\text { between sensor } \\
\text { nodes }\end{array}$ & $\begin{array}{l}\text { Managing storage } \\
\text { space, scheduling } \\
\text { of the events }\end{array}$ & Better coverage \\
\hline Resource Allocators & $\begin{array}{l}\text { Allocation of data to } \\
\text { resources from } \\
\text { gateway }\end{array}$ & $\begin{array}{l}\text { Proper allocation of } \\
\text { the processing } \\
\text { components }\end{array}$ & Proper scheduling \\
\hline WSN & $\begin{array}{l}\text { Conveying and } \\
\text { networking }\end{array}$ & $\begin{array}{l}\text { Energy efficient } \\
\text { routing }\end{array}$ & $\begin{array}{l}\text { Reduced battery } \\
\text { usage, }\end{array}$ \\
\hline Base Station & $\begin{array}{l}\text { Moving the sensed } \\
\text { data to the } \\
\text { processing layer and } \\
\text { fetching the } \\
\text { information from } \\
\text { cloud to gateway }\end{array}$ & Load balancing & $\begin{array}{l}\text { Improvement in } \\
\text { interoperability and } \\
\text { interaction }\end{array}$ \\
\hline Process Control & $\begin{array}{l}\text { Performing } \\
\text { computations and } \\
\text { allocation of servers }\end{array}$ & $\begin{array}{l}\text { Algorithms for } \\
\text { Dynamic allocation } \\
\text { of Tasks }\end{array}$ & $\begin{array}{l}\text { Improvement in } \\
\text { quality of service and } \\
\text { minimization of Cost }\end{array}$ \\
\hline Actuators & $\begin{array}{l}\text { Performing action in } \\
\text { response to stimulus }\end{array}$ & $\begin{array}{l}\text { Proper monitoring } \\
\text { and predicting of } \\
\text { energy consumption }\end{array}$ & $\begin{array}{l}\text { Privacy, security and } \\
\text { usage pattern }\end{array}$ \\
\hline
\end{tabular}

Table.2 Summary of the Green IOT Development 
IRO Journal on Sustainable Wireless Systems (2019)

Vol.01/ No. 04

Pages: 256-264

http://irojournals.com/irosws/

DOI: https://doi.org/10.36548/jsws.2019.4.006

\section{THE APPLICATIONS OF SUSTAINABLE GREEN IOT}

The green computing is the "environmental aware usage of the information and the communication technologies devices such as the computers, servers and peripherals along with other resources related to it. Some of the green computing techniques adapted in the IOT to make it sustainable are. Storage links and the virtualization of the resources such as the servers minimizing the total number of the equipment's in turn reducing the energy demands that are required for the functioning, The reduced amount of devices in turn also reduces the cost, the GHG emissions, and the time demand in the maintaining, managing of the application and the storage space. The virtualization of the desktop, the decrease in the number of consumables and the engagement of the recycling, and reuse are also proven ways of deploying the green technologies in the internet of things. The section provides the IOT applications that engage the green technologies to improve its sustainability [2]. Fig .3 shows the applications of the IOT

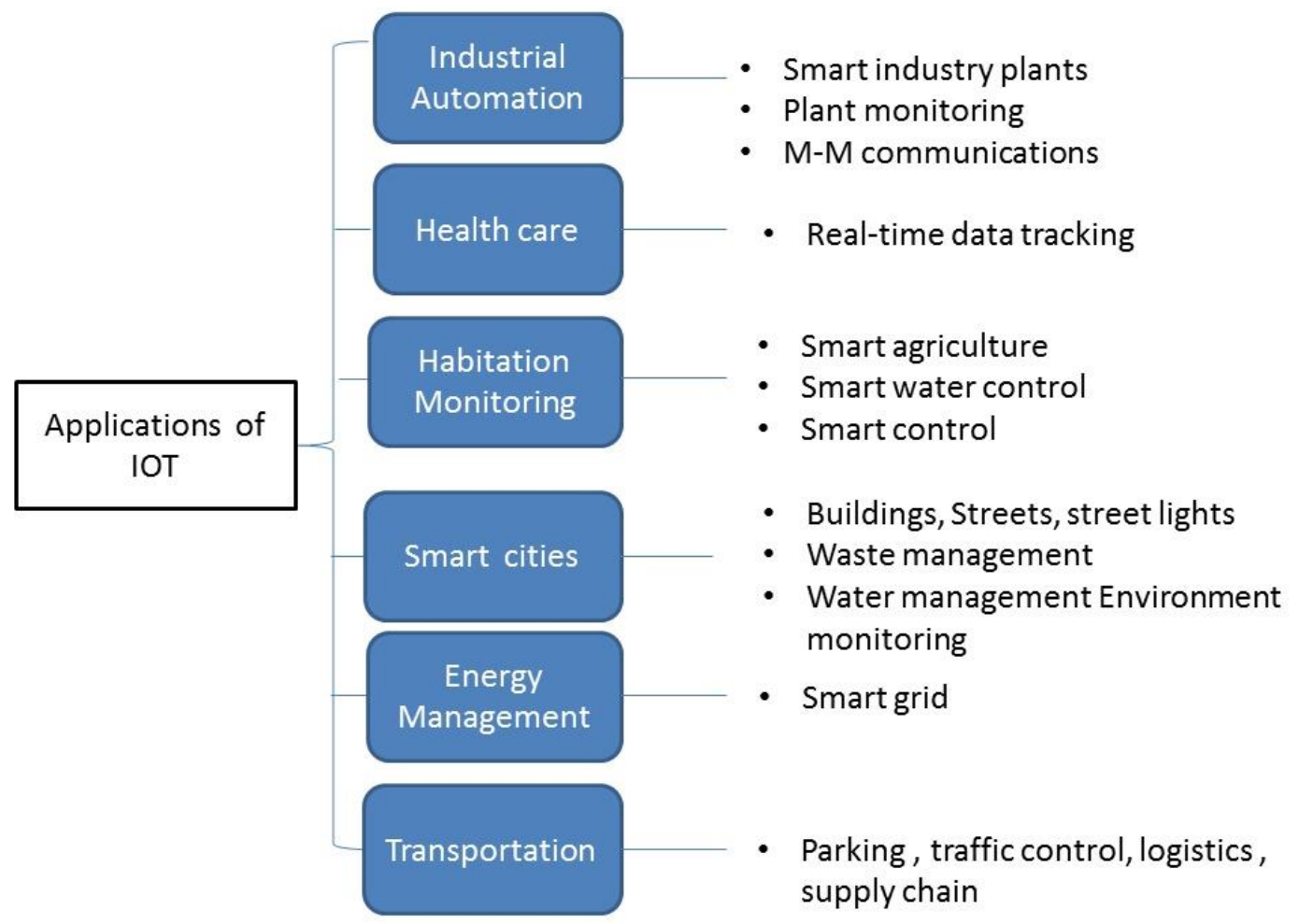

Fig.3 IOT Applications [3]

ISSN: 2582-3167 (online) 
IRO Journal on Sustainable Wireless Systems (2019)

Vol.01/ No. 04

Pages: 256-264

http://irojournals.com/irosws/

DOI: https://doi.org/10.36548/jsws.2019.4.006

The application of the green technologies is utilized in the following applications such as the industrial automation [3][9]; it is highly utilized in the agriculture [4] to make it more sustainable. The green technologies also take a vital role in the smart cities development to make it more sustainable and safe [5] [7]. The sustainability in the supply chain is achieved by employing the green internet of things [8]

\section{CHALLENGES IN DEPLOYING GREEN IOT}

The creation of green IOT to make it sustainable faces certain challenges such as the number of the sensors used, the amount of information to be generated [1]. The deployment of the green technology itself remains as an issue in the IOT [3] as the communication process consumes more power and the devices associated with an IOT [4] operate using a limited energy. Other issues related to the development of the green-IOT are the adoption and employment of the software's and the hard wares that minimizes the energy usage, progress, collaboration and the interoperability of the technologies for recognizing as well as verifying the privacy and the security. The engagement of the computing techniques and the continual progresses in the communication methodologies also serve as important issue affecting the deployment of the green-IOT [18]

\section{CONCLUSION}

The internet of things that is capable of involving billion of devices that range from large scale to small scale. The rapid progress in the technologies cause huge growth in the devices that are connected by the IOT, and in turn increases the energy consumption. Researchers have put forward many methods to reduce the energy demands of the internet of thing elements. The review in the paper provides the various researches that are been done to identify the possible procedures of reducing the power requirements of the IOT and the devices associated with it along with the applications that employ the green IOT. This review would create awareness in the creation of further smart application associated with the internet of things.

\section{References}

[1] Bol, David, Julien De Vos, François Botman, Guerric de Streel, Sébastien Bernard, Denis Flandre, and Jean-Didier Legat. "Green SoCs for a sustainable Internet-of-Things." In 2013 IEEE Faible Tension Faible Consommation, pp. 1-4. IEEE, 2013.

ISSN: 2582-3167 (online) 
IRO Journal on Sustainable Wireless Systems (2019)

Vol.01/ No. 04

Pages: 256-264

http://irojournals.com/irosws/

DOI: https://doi.org/10.36548/jsws.2019.4.006

[2] Maksimovic, M. "Greening the future: Green Internet of Things (G-IoT) as a key technological enabler of sustainable development." In Internet of things and big data analytics toward next-generation intelligence, pp. 283-313. Springer, Cham, 2018.

[3] Shaikh, Faisal Karim, Sherali Zeadally, and Ernesto Exposito. "Enabling technologies for green internet of things." IEEE Systems Journal 11, no. 2 (2015): 983-994.

[4] Maksimović, Mirjana, and Enisa Omanović-Mikličanin. "Green internet of things and green nanotechnology role in realizing smart and sustainable agriculture." In VIII International Scientific Agriculture Symposium "AGROSYM 2017, pp. 2290-2295. 2017.

[5] Maksimovic, Mirjana. "The role of green internet of things (G-IoT) and big data in making cities smarter, safer and more sustainable." International Journal of Computing and Digital Systems 6, no. 04 (2017): 175-184.

[6] Peoples, Cathryn, Gerard Parr, Sally McClean, B. Scotney, and P. Morrow. "Performance evaluation of green data centre management supporting sustainable growth of the internet of things." Simulation Modelling Practice and Theory 34 (2013): 221-242.

[7] Silva, Bhagya Nathali, Murad Khan, and Kijun Han. "Towards sustainable smart cities: A review of trends, architectures, components, and open challenges in smart cities." Sustainable Cities and Society 38 (2018): 697-713.

[8] Manavalan, E., and K. Jayakrishna. "A review of Internet of Things (IoT) embedded sustainable supply chain for industry 4.0 requirements." Computers \& Industrial Engineering 127 (2019): 925953.

[9] Zarei, M., Mohammadian, A. and Ghasemi, R., 2016. Internet of things in industries: A survey for sustainable development. International Journal of Innovation and Sustainable Development, 10(4), pp.419-442.

[10] Kyriazis, Dimosthenis, and Theodora Varvarigou. "Smart, autonomous and reliable Internet of Things." Procedia Computer Science 21 (2013): 442-448.

[11] Zhu, Chunsheng, Victor CM Leung, Lei Shu, and Edith C-H. Ngai. "Green internet of things for smart world." IEEE Access 3 (2015): 2151-2162.

[12] Huang, Jun, Yu Meng, Xuehong Gong, Yanbing Liu, and Qiang Duan. "A novel deployment scheme for green internet of things." IEEE Internet of Things Journal 1, no. 2 (2014): 196-205.

[13] Ahlgren, Bengt, Markus Hidell, and Edith C-H. Ngai. "Internet of things for smart cities: Interoperability and open data." IEEE Internet Computing 20, no. 6 (2016): 52-56.

[14] Benkhelifa, Elhadj, Mohamed Abdel-Maguid, Stanley Ewenike, and D. Heatley. "The Internet of Things: The eco-system for sustainable growth." In 2014 IEEE/ACS 11th International Conference on Computer Systems and Applications (AICCSA), pp. 836-842. IEEE, 2014.

ISSN: 2582-3167 (online) 
IRO Journal on Sustainable Wireless Systems (2019)

Vol.01/ No. 04

Pages: 256-264

http://irojournals.com/irosws/

DOI: https://doi.org/10.36548/jsws.2019.4.006

[15] Alzboon, MB Mowafaq Salem, Saleh Ali Alomari, Mohammad Subhi Al-Batah, and Mustafa Banikhalaf. "The Characteristics of The Green Internet of Things and Big Data in Building Safer, Smarter, and Sustainable Cities." International Journal of Engineering \& Technology 6, no. 3 (2017): 83-92.

[16] Kyriazis, Dimosthenis, Theodora Varvarigou, Daniel White, Andrea Rossi, and Joshua Cooper. "Sustainable smart city IoT applications: Heat and electricity management \& Eco-conscious cruise control for public transportation." In 2013 IEEE 14th International Symposium on" A World of Wireless, Mobile and Multimedia Networks"(WoWMoM), pp. 1-5. IEEE, 2013.

[17] Ahmad, Rafeeq, Mohd Asim Asim, Safwan Zubair Khan, and Bharat Singh. "Green IoT_-Issues and Challenges." Available at SSRN 3350317 (2019)..

[18] Abedin, Sarder Fakhrul, Md Golam Rabiul Alam, Rim Haw, and Choong Seon Hong. "A system model for energy efficient green-IoT network." In 2015 International Conference on Information Networking (ICOIN), pp. 177-182. IEEE, 2015.

[19] Prasad, Shyam Sundar, and Chanakya Kumar. "A green and reliable internet of things." Communications and Network 5, no. 01 (2013): 44.

[20] Nandyala, Chandra Sukanya, and Haeng-Kon Kim. "Green IoT agriculture and healthcare application (GAHA)." International Journal of Smart Home 10, no. 4 (2016): 289-300.

[21] Arshad, Rushan, Saman Zahoor, Munam Ali Shah, Abdul Wahid, and Hongnian Yu. "Green IoT: An investigation on energy saving practices for 2020 and beyond." IEEE Access 5 (2017): 15667-15681.

[22] Al-Turjman, Fadi, Enver Ever, and Hadi Zahmatkesh. "Green Femtocells in the IoT Era: Traffic Modeling and Challenges--An Overview." IEEE Network 31, no. 6 (2017): 48-55.

ISSN: 2582-3167 (online) 